\title{
Understanding the use of strategic intelligence as a strategic management tool in the long-term insurance industry in South Africa
}

\author{
Authors: \\ René Pellissier ${ }^{1}$ \\ J-P. Kruger ${ }^{1}$ \\ Affiliations: \\ ${ }^{1}$ Department of Business \\ Management, University of \\ South Africa, South Africa \\ Correspondence to: \\ René Pellissier \\ Email: \\ pellir@unisa.ac.za \\ Postal address: \\ PO Box 392, UNISA 0003, \\ South Africa \\ Dates: \\ Received: 25 May 2010 \\ Accepted: 08 Mar. 2011 \\ Published: 11 Oct. 2011 \\ How to cite this article: \\ Pellisier, R. \& Kruger, J-P., \\ 2011, 'Understanding the use \\ of strategic intelligence as a \\ strategic management tool \\ in the long-term insurance \\ industry in South Africa', \\ SA Journal of Information \\ Management 13(1), Art. \\ \#426, 13 pages. doi:10.4102/ \\ sajim.v13i1.426
}

C 2011. The Authors. Licensee: AOSIS OpenJournals. This work is licensed under the Creative Commons Attribution License.
The purpose of this research paper was to explore the extent to which strategic intelligence is utilised within the South African long-term insurance industry and whether it could be used to identify opportunities or threats within the global environment to remain competitive, create greater innovation, and corporate advantage.

The paper obtained the qualitative views and opinions of strategic decision makers, on an executive managerial level within the South African long-term insurance industry, on their organisations use of strategic intelligence. It was found that there are marked differences in the conformity and usage of strategic intelligence and its components between the organisations surveyed, with a measurable difference between large and small organisations. It is, however, generally viewed that the use of a strategic intelligence framework could greatly enhance decision-making.

Data collection for the research undertaken was limited to the 82 long-term insurance companies, which were registered with the South African Financial Services Board. More specifically the focus was on the organisations listed on the Johannesburg Securities Exchange within the Life Assurance sector, within which a final response rate of $36.1 \%$ was achieved, including the $100 \%$ response rate from the six listed organisations.

By understanding the extent to which strategic intelligence is utilised in the South African longterm insurance industry, and the benefits or problems that are experienced by implementing and using strategic intelligence as an input to the strategic management process we can comprehend the value that strategic intelligence adds in the decision making process. The originality of this work concludes in the identification and utilisation of the most important factors of a strategic intelligence framework that will greatly enhance global corporate decisionmaking and result in competitive advantage and constant innovation within the South African business environment.

\section{Topic}

Strategic intelligence has information as its foundation. This research proposes that, through its ability to absorb sources of information, the synergy of business intelligence, competitive intelligence, and knowledge management combined to form strategic intelligence, will allow organisations to incorporate all of their information and intellectual capital into a single, easily manageable system to meet the intelligence requirements of management's strategic planning and decision-making process.

This research reviews the current understanding and implementation of strategic intelligence systems and processes in the South African long-term insurance industry. This review is performed in order to identify problems experienced and advantages incurred by executive management through the implementation and use of strategic intelligence as an input to the strategic management process. The study further sets out to determine the value of strategic intelligence in the decision-making process. A purposive sampling technique was used to select the six most important organisations in the South African long-term insurance industry. This industry was selected because of its strong focus on information and knowledge, and the agility with which decisions need to be made in order to cope with environmental and technological changes.

We found that most organisations have not embraced any framework for a strategic intelligence system or portal that provide valid strategic intelligence, which could assist in creating competitive advantage and constant innovation. Our research shows that through its ability 
to absorb sources of information, the synergy of business intelligence, competitive intelligence, and knowledge management combined to form strategic intelligence, will allow organisations to incorporate all of their information and intellectual capital into a single database or system which will meet the intelligence requirements of management.

\section{Research statement}

The identification and utilisation of the most important factors of a strategic intelligence framework will greatly enhance global corporate decision-making and result in competitive advantage and constant innovation within the South African business environment.

\section{Methodology}

Research is undertaken to increase knowledge, and is based on logical relationships and not just one's personal beliefs. Research involves methods and designs to collect data; arguments as to why results obtained are correct and meaningful, and an explanation of the limitations associated with the research (Leedy \& Omrod 2005; Saunders, Lewis \& Thornhill 2007).

Research identifies the need to find things out, such as the answers to a number of questions, which suggests a number of purposes for the research (Saunders et al. 2007).

The South African business environment comprises many industries and for the purpose of this study the long-term insurance industry was selected. The population was selected as a representative of the greater South African business environment as the organisations in this industry are vulnerable to changes within the macro-environment and micro-environment, are undergoing intense changes within their market and regulatory environment, and their competitive advantage are based on their use of information gathered on these environments.

The primary aim of this research study is to explore the extent to which strategic intelligence is currently utilised within the South African long-term insurance industry and how it can be used to identify opportunities or threats within the global environment to remain competitive, create greater innovation, and corporate advantage.

The following primary research questions were generated from the aforementioned aim:

- What is the extent to which strategic intelligence is utilised within the South African long-term insurance industry?

- How does strategic intelligence form a vital component of strategic management?

- What value does strategic intelligence add to the strategic management process within the South African long-term insurance industry?

Based on the primary research questions listed, the secondary research questions were generated:
- How do South African long-term insurance organisations currently collect and create strategic intelligence?

- What information systems are currently utilised by South African long-term insurance organisations to create strategic intelligence?

- How strategic decisions are made in South African longterm insurance organisations and on what intelligence are these decisions based?

- How South African long-term insurance organisations can best implement strategic intelligence?

A purposive sampling technique was used to select the best cases that would enable the research questions to be answered and result in the research objectives being met. As a homogeneous group, the long-term insurance industry was selected as the target population for the study and the individual organisations approached were identified from the list of valid licenses registered with the Financial Services Board. The unit of analysis was the selected organisations provided by the Financial Services Board. There are 82 long-term insurance companies in South Africa, of which six organisations were listed on the Johannesburg Securities Exchange within the Life Assurance Sector. The listed companies include: Old Mutual Plc., Liberty Group Ltd, Sanlam Ltd, Discovery Holdings Ltd, Clientele Life Ltd, and Metropolitan Holding Ltd.

The selected organisations participated in the research survey and completed the questionnaire. The research goal was therefore met with a $100 \%$ response rate. To broaden the scope of the research, the sample size was increased to include all the 82 long-term insurance companies that were registered with the Financial Services Board, which provided an in-depth examination of the use of strategic intelligence within the long-term insurance industry. Within the research results a distinction is made based on the size of the organisation in the South African context with larger organisations having more than 500 employees, whilst smaller organisations have fewer than 500 employees. It is; however, important to stress that the focus of the study was on the larger listed companies, because of their size, turnover, agility and expected efficiencies in this field. The unlisted companies were included to provide a broader range of perspectives into the respective field, and the execution of such in smaller companies. Of these 82 , three had closed down before the study was conducted, four organisations confirmed that whilst they did have long-term insurance licences they were not part of the industry, and 14 companies were subsidiaries or divisions of the larger organisations and as such their answers were included with those of the larger organisations. Subtracting these 21 companies from the total sample of 82 left a sample size of 61 organisations. A final response rate of $36.1 \%$ was achieved, including the $100 \%$ response rate from the six listed organisations.

Strategic intelligence is most often used during the strategic management and strategic decision-making processes which executive and senior management conducts. As a result of the nature of the information being requested, the survey was conducted across the executive managerial level within 
the sample organisations with a focus on strategic decision makers.

Research data were collected by means of descriptive research, using a (nonprobability) purposive sample of the long-term insurance industry. A large sample was not required for this research because of the focus of this research being on gathering in-depth of information, based on a purposive sample of the long-term insurance industry. A web-based questionnaire was used to collect the data. It is important to note that a comprehensive definition list was included with the questionnaire to enhance the clarity of the terminology used in the survey. The data received from the 22 completed questionnaires were subsequently captured and analysed with the use of the statistical software program SPSS, version 16.0. This software package was used for data coding, data capturing, statistical analysis and internal consistency testing.

The variables from the questionnaire were firstly identified and coded. Secondly, the data was captured into SPSS and cleaned up to assure no anomalies were present. Because a nonprobability sampling technique (purposive sample) was used to select the respondents for the study, no generalisation was possible, and hence no inferential statistical techniques were performed.

In terms of Cross-tabulation Analysis, all variables used in the questionnaire were tabulated against each other, and were individually analysed to identify any relationships. Only variable relationships with scores greater than 7 were used in the analysis (i.e. respondents gave similar Likert scale scores for both variables), as this cut-off was viewed as having the greatest significance. As the sample was not random the significance of the relationship could not be tested by means of the Chi-square test for independence. Furthermore, a correlation matrix was used to simplify the identification of relationships, and analysis focused on relationships that fall into the -1.0 to -0.7 and +0.7 to +1.0 categories, which indicate highly negative or highly positive linear relationships.

In the context of validity in this research study, the questionnaire was tested for face validity, content validity and construct validity. This was performed through a process of pretesting the research instrument by piloting it to a small number of individuals. The comments received from these individuals lead to minor adjustments being made, after which it was distributed to the sample. Furthermore, the internal consistency of the Likert-scale items in each section was measured by means of the Cronbach Alpha Coefficient. The results showed that Cronbach's alpha reliability coefficient was high (above 0.8) for all the sections, meaning that each section shows good internal consistency.

After an introduction to the topic the research results will be analysed according to the structure used in the questionnaire format. The different parts and sections, which comprised the questionnaire, include: strategic management and strategic decision-making, business intelligence, competitive intelligence, knowledge management and strategic intelligence.

\section{Introduction}

The world has experienced a radical shift in the basic foundations of how business is conducted. The globalisation of markets and production resulted in national markets being integrated into a single global market trading in global products. The shift has been strengthened through the decline of trade barriers and fundamental developments in communication, information and transportation technologies. Globalisation resulted in greater world output, foreign investment, greater imports and exports and immense competitive pressures both between nations and industries (Hill 2005; Pearce \& Robinson 2005).

Advancements in information technology and related developments in communications technology have increased organisations' ability to link global operations into sophisticated information networks. This, in turn, shrinks the time in which information is collected and enables organisations to achieve tight coordination in worldwide operations (Hill 2005; Laudon \& Laudon 2007; Pearce \& Robinson 2005). External factors influence the organisations' direction, organisational structure and internal processes. These factors that exist in the organisations' remote, industry and operating environments require constant monitoring for the formulation of strategies to optimise the organisations market opportunities and threats to allow them to survive in their competitive environment (Pearce \& Robinson 2005).

In the current information age in which knowledge is power, where utilisation of this knowledge adds value to decisionmaking, organisations employ information to expand and maintain a competitive advantage (Haag, Cummings \& Philips 2007). Gathering information and turning this raw data into intelligence through an exercise of human judgement, is a fundamental aspect of business (Murphy 2005). Knowledge and information are vital components in creating wealth for organisations. By utilising information systems in the process of generating knowledge and intelligence, the abundance of available information will allow organisations to generate competitive advantage and constant innovation to survive and prosper in the long term (Laudon \& Laudon 2007).

An organisation needs to have knowledge about its business environment (its activities, resources, markets, customers, products, services, and costs) to plan for its current and future success. This knowledge, which could allow for the organisation's successful functioning needs to be disseminated organisation-wide. This results in one of the basic challenges for senior management; how to create a mindset about the present and the future in order to anticipate trends and the directions to be taken (Tham \& Kim 2002).

\section{Strategic intelligence}

Strategic intelligence can be viewed as what a company needs to know of its business environment to enable it 
to gain insight into its present processes, anticipate and manage change for the future, design appropriate strategies that will create business value for customers, and improve profitability in current and new markets (Tham \& Kim 2002).

Strategic intelligence consists of the aggregation of the various types of intelligentsia, which creates a synergy between business intelligence, competitive intelligence, and knowledge management to provide value-added information and knowledge toward making organisational strategic decisions. Strategic intelligence signifies the creation and transformation of information or knowledge that can be used in high-level decision-making. The emphasis is on how best to position the organisation to deal with future challenges and opportunities to maximise the organisation's success (Liebowitz 2006). Xu and Kaye (2009:12) define strategic intelligence as 'strategically significant information [provided] to senior managers that is scanned, analysed, digested, and is meaningful that could affect senior managers' beliefs, commitments, and actions'.

Strategic intelligence is identified as having the correct information available for the correct people as to allow them to make informed business decisions about the future of their organisations. Without this information, it is believed that it would be difficult for employees to make the correct decisions to achieve and maintain market leadership (Marchand \& Hykes 2007). The value of strategic intelligence can therefore be seen through the improvement of the capabilities of managers and workers to learn about potential changes within their business or industry environment without having to redefine intelligence on which previous decisions were based. With the ability to openly share their perceptions, new information and insights whenever and wherever the organisation requires such information will increase the 'intelligence quotient' of all organisational managers (Tham \& Kim 2002). Strategic intelligence's interest is less on the present than on the past and on the future, with a time horizon spanning two years in the past and to five to 10 years in the future. By collecting and analysing data from the past, the organisation can evaluate the success (or failure) of its strategies and those of its competitors. This will permit the organisation to better weigh its options for the future (McGonagle \& Vella 1999).

\section{The South African long-term insurance industry}

Worldwide, the long-term insurance industry has undergone many changes in its working model. These changes are primarily linked to increasing the attractiveness of the industry to consumers. With the advent of technological advances that allow all consumers to shop around for the best products and pricing and the globalisation of markets allowing organisations to compete globally, organisations in this industry are required to stay a step ahead of their competitors by remaining agile and employing information and knowledge for strategic use. Consequently, a number of strategic decisions will have to be made in order to remain competitive in the foreseeable future. New products, allowing consumers a greater understanding, flexibility and visibility will be required to attract new clients as well as increase market share and remain competitive. However, the utilisation of strategic intelligence during the strategic management process could identify opportunities, and challenges faced. This again, leads to better informed, effective decisions to be made that will assist organisations in gaining greater market share and to compete successfully against local and international competitors.

The modern business environment within the South African long-term insurance market has often been turbulent and volatile. South African organisations are required to engage international and local competitors and customers in a more regulated manner, and despite years of experience in the local environment, even the most successful and established organisations have committed strategic errors in both the local and international markets. An example of this includes a number of local organisations that have faced some difficulty as a result of their offshore subsidiaries having suffered under the financial crisis during the period 2007-2009. This was mainly as a result of a lack of managerial awareness and foresight. Certain organisations have since reviewed their strategies and refocused, or closed down certain divisions. Furthermore, the long-term insurance industry is facing many challenges and changes. For instance, compliance with regulatory requirements, increased competition, the Financial Sector Charter, the International Financial Reporting Standards (IFRS 4), addressing the needs of the low-income market for appropriate products, emerging technologies, inflation and interest rate increases and fluctuations, and, lastly, the Statement of Intent requirements as agreed upon by the Minister of Finance and the Life Offices' Association of South Africa rebuilding public confidence, dealing with issues emanating from the determinations made by the Pension Fund Adjudicator, consumerism and the impact of the global financial market crisis (The Financial Services Board South Africa 2007).

A media release by the Life Offices' Association (Life Offices' Association of South Africa 2008) in February 2008 revealed that South Africa has an insurance gap of more than R10trillion, by means of life and disability insurance. Whilst the industry has made large gains in the past years, a large insurance deficit is still looming, allowing organisations the opportunity to further increase their market share.

Strategic intelligence has information as its foundation. Information can be collected from both internal and external sources such as: transaction processing, financial or supply chain systems and external databases of customer, product, and supplier information or by further utilising tools such as Michael Porter's Five Forces Model or Value chain analysis to create value by converting data into information. By collecting all this information into a single data warehouse or strategic intelligence repository that combines all the best aspects of strategic intelligence and information systems, a single databank will be created that would align them to 
provide business with the information and even intelligence it requires (Liebowitz 2006).

This research proposes that, through its ability to absorb sources of information, the synergy of business intelligence, competitive intelligence, and knowledge management combined to form strategic intelligence, will allow organisations to incorporate all of their information and intellectual capital into a single database or system which will meet the intelligence requirements of management. Montgomery and Weinberg (1998) gave an insight into the working or design of a strategic intelligence System, and Liebowitz (2006) and Marchand and Hykes (2007) identified the basis of strategic intelligence. Yet, the researchers are of the opinion that organisations have not yet fully embraced this model for a fully cooperative global internal corporate strategic intelligence system or portal that will incorporate all aspects of strategic intelligence into a single, easily manageable resource for management's strategic planning and decision-making process. This is the subject of this research.

\section{Empirical research results Strategic management}

The first section of the questionnaire was designed to gain an understanding of the extent to which respondents undertake strategic management within the long-term insurance industry. The results suggest that:

- respondents, to a large extent, utilise a formalised strategic management process

- respondents recognise strategic management as a necessary activity for business

- respondents view information as having strategic value

- respondents believe that good strategy hinges on having timely, relevant and high quality information

- respondents attempt to provide their managers with critical and relevant information for strategic decision making; however, smaller organisations that were in greater disagreement do not have the capacity to provide managers with the required information, as larger organisations do

- the majority of respondents believe that they do provide their managers with access to information that provides them a comprehensive and robust perspective on how the organisation is performing, the dynamics at play in the market place, competitor behaviour, stakeholder perceptions, resource availability, and the implications of trends in these areas for the firm; however, smaller organisations are at a disadvantage to larger organisations.

The results indicate that strategic management is to a large extent utilised within organisations in the long-term insurance industry; however, smaller organisations are at a disadvantage with regards to the provision of information to management.

\section{Business intelligence}

The purpose of the second section of the questionnaire was to gain an understanding into the business intelligence activities that are undertaken by the organisations within the long-term insurance industry. Based on the results obtained, the results suggest that:

- respondents collect and utilise business intelligence in decision-making; however, the results distinctly provide evidence that larger organisations make greater use of business intelligence than smaller organisations

- respondents, in general, have business intelligence that is valid, reliable and actionable ${ }^{1}$

- the majority of respondents believed that the availability of business intelligence increased the effectiveness of managerial decision-making

- a greater proportion of organisations did not have a predefined dashboard view of their organisations, than those that $\mathrm{did}^{2}$; however, the respondents unanimously agreed that a predefined dashboard view of the organisation is important for managerial decision-making

- a large number of different software applications were used by respondents to gather and generate business intelligence.

The results indicate that business intelligence is to a large extent utilised within organisations in the long-term insurance industry. Further questions exposed that larger organisations make greater use of business intelligence than smaller organisations, and therefore have a much greater competitive advantage as a result of their: access to valid, reliable and actionable business intelligence, predefined dashboard views of their organisations, and software applications used.

1. However, a large gap occurred between the results provided by smaller organisations and those of large organisations. Thus, proving that smaller organisations do not have business intelligence that is valid, reliable and actionable.

2.The respondents unanimously agreed that a predefined dashboard view of the organisation is important for managerial decision-making.

\begin{tabular}{|c|c|c|c|}
\hline Variable & Question & Mean & SD \\
\hline \multicolumn{4}{|c|}{ Section 1: Strategic management and strategic decision-making } \\
\hline 3.1 .3 & Our organisational views information as having strategic value. & 4.36 & 0.658 \\
\hline 3.1 .2 & Our organisation recognises strategic management as a necessary activity for business. & 4.27 & 0.703 \\
\hline 3.1 .4 & We believe that good strategy hinges on having timely, relevant and high quality information. & 4.23 & 0.685 \\
\hline 3.1 .1 & We utilise a formalised strategic management process. & 3.91 & 0.811 \\
\hline 3.1 .5 & Our organisation provides its managers with critical and relevant information for strategic decision making. & 3.36 & 0.953 \\
\hline 3.1 .6 & $\begin{array}{l}\text { We believe our organisation provides our managers with access to information that provides a comprehensive } \\
\text { and robust perspective on how the organisation is performing, the dynamics at play in the market place, } \\
\text { competitor behaviour, stakeholder perceptions, resource availability and the implications of trends in these areas } \\
\text { for the firm. }\end{array}$ & 3.27 & 1.032 \\
\hline
\end{tabular}


TABLE 2: Business intelligence sorted by mean scores.

\begin{tabular}{|c|c|c|c|}
\hline Variable & Question & Mean & SD \\
\hline \multicolumn{4}{|c|}{ Section 2: Business intelligence } \\
\hline 3.2.5 & We believe there is value in having a predefined dashboard view of our organisation. & 4.14 & 0.889 \\
\hline 3.2.1 & We collect and utilise business intelligence in decision making. & 3.50 & 1.102 \\
\hline 3.2.3 & The availability of business intelligence has increased the effectiveness of managerial decision making. & 3.50 & 1.102 \\
\hline 3.2.2 & Our business intelligence is valid, reliable and actionable. & 3.36 & 1.217 \\
\hline 3.2.4 & We have a predefined dashboard view of our organisation. & 2.86 & 1.424 \\
\hline
\end{tabular}

SD, standard deviation.

\section{Competitive intelligence}

The purpose of section three of the questionnaire was to gain an understanding of the competitive intelligence activities that take place within organisations within the long-term insurance industry. The results suggest that:

- larger organisations do have a formal competitive intelligence function, whereas smaller organisations (in general) do not have a formalised competitive intelligence function

- a high number of organisations do make use of competitive intelligence in decision-making even if no formalised function exists for the management of competitive intelligence

- too few organisations have achieved the task of timely creation and distribution of competitive intelligence to management, with larger organisations having greater success in this area

- the vast majority of organisations do utilise external sources of information for market research

- a large number of organisations do evaluate the reliability and accuracy of their sources of information

- large organisations seem to analyse their competitors and have up to date profiles of them, whilst smaller organisations mostly did not

- most organisations are up to date with emerging technologies in their field of business and the benefits or features of these technologies

- organisations are cognisant of new and pending government legislation and legislative trends that impact their organisation

- the most important sources for the collection of competitive intelligence included the analysis of competitor's products $(86 \%)$, websites $(86 \%)$, annual reports $(77 \%)$ and research reports $(72 \%)$

- the most common analytical methods or models used within the organisations to generate competitive intelligence included SWOT analysis and competitor analysis (both with $82 \%$ ), customer segmentation analysis $(72 \%)$, industry analysis (64\%), and financial analysis and valuation $(59 \%)$

- the most popular methods used by organisations to distribute and present intelligence results were email (77\%), presentations $(72 \%)$, and reports $(64 \%)$

- very few organisations made use of competitive intelligence software applications.

The results indicate that competitive intelligence activities are more prevalent in a formalised manner in larger organisations in the long-term insurance industry, whilst smaller organisations make much greater use of competitive intelligence on a ad hoc, or when required, basis.

\section{Knowledge management}

The purpose of this section of the questionnaire was to gain an understanding of the knowledge management activities that take place within the organisations in the long-term insurance industry. Based on the results obtained, the results suggest that:

- there is strong evidence that organisations believe that knowledge management assists in creating value out of their organisations intangible assets

- organisations view knowledge as a strategic tool

- the majority of organisation's organisational culture is conducive to the sharing of knowledge

- overall, the organisations benefit from the processes created to contribute knowledge

- the majority of organisations did not have a central intelligence repository to which employees were able to contribute or access knowledge

- employees were generally not aware of the benefits of business intelligence and competitive intelligence, which points towards a lack of internal education or marketing

TABLE 3: Competitive intelligence sorted by mean scores.

\begin{tabular}{|c|c|c|c|}
\hline Variable & Question & Mean & SD \\
\hline \multicolumn{4}{|c|}{ Section 3: Competitive intelligence } \\
\hline 3.3.8 & $\begin{array}{l}\text { Our organisation is cognisant of new and pending government legislation and legislative trends that impact our } \\
\text { organisation. }\end{array}$ & 4.59 & 0.666 \\
\hline 3.3.4 & Our organisation utilises external sources of information for market research (research companies). & 3.91 & 1.109 \\
\hline 3.3.2 & Our organisation makes use of competitive intelligence in decision-making. & 3.45 & 1.101 \\
\hline 3.3.7 & $\begin{array}{l}\text { We are up to date with emerging technologies in our field of business and the benefits/features of these } \\
\text { technologies. }\end{array}$ & 3.41 & 0.959 \\
\hline 3.3.6 & We analyse our competitors and have up to date profiles of them. & 3.23 & 1.020 \\
\hline 3.3.3 & Our competitive intelligence is created and distributed to management in a timely fashion. & 3.00 & 1.195 \\
\hline 3.3.1 & $\begin{array}{l}\text { Our organisation has a formal competitive intelligence function (which utilises a standardised competitive } \\
\text { intelligence process or framework). }\end{array}$ & 2.59 & 1.368 \\
\hline
\end{tabular}

SD, standard deviation. 
with regards to the benefits of business and competitive intelligence

- a large number of organisations do require their employees to be personally responsible for the transfer and storage of knowledge in their area of speciality

- it seems as though there are a number of organisations that have an environment in which employees do not contribute regular information ${ }^{3}$

- smaller organisations are least likely to have a document management system in place

- most organisations do not have a process in place for the conversion of individually held competence to systems, tools, or templates, do not store intellectual capital, conduct internal knowledge audits or use specific knowledge management software applications but a number made use of in house data stores such as a central file repository on the corporate intranet, Microsoft SharePoint Portal, and in house systems to store and manage knowledge.

The results indicate that the vast majority of organisations in the long-term insurance industry do believe that knowledge management provides value as a strategic tool, and had a culture conducive to knowledge sharing where employees are responsible for contributing knowledge in their specific area of expertise. However, the results show that employees are often not aware of the benefits of their contributions, and that they do not regularly contribute information. The results also showed that most of the organisations lacked internal systems dedicated to the collection and storage of knowledge, which could contribute to the lack of knowledge contributed by employees.

\section{Strategic intelligence}

The purpose of this section was to gain an understanding of the strategic intelligence activities that take place within organisations in the long-term insurance industry. Based on the results obtained, the results suggest that:

- strategic intelligence processes are more prevalent in larger organisations

3.This is discouraging as employees are often privy to valuable information, whilst those that do encourage contributions could find themselves with a competitive those that do encourage coy advantage, whilst and an equal number of organisations do have and do not have facilities available to their employees to enable the sharing of knowledge with smaller organisations the least likely to have access to the correct technica infrastructure.
- respondents do not, on average, consolidate all their intelligence into a single Intelligence repository

- the majority of respondents do not fuse their business intelligence, competitive intelligence and knowledge management (to create strategic intelligence) for use in decision-making

- respondents believe that strategic intelligence, as a collective, provides better information input to decision makers

- not all intelligence gathered is checked for accuracy

- the majority of respondents did not have a long-term strategic intelligence plan

- strategic intelligence is not used at all levels of decisionmaking

- a growing proportion of managers use strategic intelligence in their strategic planning and decision-making

- strategic intelligence does assist managers to forge better, fact-based decisions

- strategic intelligence engages managers in the strategy development process

- strategic intelligence assists managers to quantify and qualify strategic choices and articulate strategies

- key decision makers are not always surveyed or interviewed to verify that the intelligence products produced for them satisfy their needs

- strategic intelligence does not form part of the respondents performance appraisal review process

- strategic intelligence can sharpen internal performance monitoring

- strategic intelligence is not a continuous activity in the respondent's organisation

- organisations do not, on average, have dedicated human resources to maintain their Strategic Intelligence function or process

- very few respondents would consider outsourcing their strategic intelligence function

- the respondents linked strategic intelligence requirements to their strategic objectives and their long term goals, believe that the use of strategic intelligence can lead to competitive advantage and innovation, enhances decision-making, plays a critical role in the strategic

TABLE 4: Knowledge management sorted by mean scores.

\begin{tabular}{|c|c|c|c|}
\hline Variable & Question & Mean & SD \\
\hline \multicolumn{4}{|c|}{ Section 4: Knowledge management } \\
\hline 3.4 .2 & We view knowledge as a strategic tool. & 4.14 & 0.710 \\
\hline 3.4 .1 & We believe that knowledge management assists in creating value out of our organisations intangible assets. & 4.09 & 0.610 \\
\hline 3.4.3 & Our organisational culture is conducive to the sharing of knowledge. & 3.32 & 0.995 \\
\hline 3.4.4 & Our organisation benefits from the processes created to contribute knowledge. & 3.18 & 1.006 \\
\hline 3.4.7 & Employees are personally responsible for the transfer and storage of knowledge in their area of speciality. & 3.18 & 1.220 \\
\hline 3.4.8 & Employees regularly report information they have found. & 3.09 & 1.065 \\
\hline 3.4.10 & Our organisation has a document management system in place. & 2.82 & 1.220 \\
\hline 3.4 .9 & Our organisation has the technical infrastructure to enable knowledge sharing. & 2.77 & 1.307 \\
\hline 3.4.12 & Our organisation stores intellectual capital. & 2.73 & 1.120 \\
\hline 3.4.6 & Employees are aware of the benefits of business intelligence and competitive intelligence. & 2.64 & 1.049 \\
\hline 3.4.5 & $\begin{array}{l}\text { Knowledge and intelligence is contributed and accessed by employees by means of a central intelligence } \\
\text { repository (which acts as a pool of corporate information). }\end{array}$ & 2.45 & 1.101 \\
\hline 3.4.11 & We have a process in place for the conversion of individually held competence to systems, tools, or templates. & 2.36 & 1.177 \\
\hline 3.4.13 & $\begin{array}{l}\text { We conduct an internal knowledge audit (e.g. identify and catalogue what people know, what reports they } \\
\text { have, publications). }\end{array}$ & 2.14 & 1.246 \\
\hline
\end{tabular}

SD, standard deviation. 
management process, is most commonly used by the organisations during new product development (95\%), when considering competitive advantage (68\%), when determining pricing strategies $(64 \%)$, and when considering market entry strategies (64\%)

- strategic intelligence was predominately utilised at a strategic level as an input to decision-making and has its greatest impact at a strategic level

- respondents believed further research should be conducted to identify better methods of implementing strategic intelligence, but that most organisations did not make use of any strategic intelligence software applications or methods and/or models.

The results indicate that the majority of organisations in the long-term insurance industry agree that strategic intelligence is an important component to strategic decision-making. Strategic intelligence can therefore provide their management with better information input that could lead to competitive advantage and innovation. Even so, only a few of the larger organisations have formalised processes or systems in place for the formation and use of strategic intelligence.

\section{Key results}

In the previous section, the analysed empirical results of the research survey were discussed in detail. Whilst the results provide interesting findings on their own, the basis of this research is to provide feedback and evidence to answer the research questions based on the research aim. The findings of the empirical results will be discussed per intelligence stream, to provide a detailed understanding of how data and information is collected and transformed into strategic intelligence, in order to answer the research questions.
The results indicate that the intelligence stream, which is most predominantly focused upon, is Business Intelligence, with the majority of respondents collecting Business Intelligence. The results indicate that a number of systems are used to transform the Business Intelligence data into intelligence, which is found to be valid, actionable and reliable. However, a greater proportion of organisations did not transform the data into a predefined dashboard view of their organisations, than those that did, who unanimously agreed that a predefined dashboard view of the organisation is important for managerial decision-making. The results provide evidence that larger organisations make greater use of Business Intelligence than smaller organisations.

\section{How data and information are collected and transformed into strategic intelligence}

Data and information are the basic building blocks, which are collected and analysed to form actionable intelligence. Strategic intelligence is comprised of different sources of data, including internal business intelligence, external competitive intelligence, and employee and organisational knowledge, which should be combined to provide the organisational decision makers with accurate intelligence on which to base their decisions.

From a competitive intelligence viewpoint, the results indicate that too few organisations have achieved the task of timely creation and distribution of competitive intelligence to management, with larger organisations having greater success in this area. Furthermore, the majority of organisations utilise external sources of information for market research, with the most important sources for the collection of competitive intelligence including the analysis of competitor's products

TABLE 5: Strategic Intelligence sorted by mean scores.

\begin{tabular}{|c|c|c|c|}
\hline Variable & Question & Mean & SD \\
\hline \multicolumn{4}{|c|}{ Section 5: Strategic intelligence } \\
\hline 3.5.4 & We believe that strategic intelligence, as a collective, provides better information input to decision makers. & 3.95 & 0.785 \\
\hline 3.5 .20 & Strategic intelligence enhances decision-making. & 3.95 & 0.844 \\
\hline 3.5.9 & We believe strategic intelligence assists managers forge better, fact-based decisions. & 3.91 & 0.750 \\
\hline 3.5.21 & Strategic intelligence plays a critical role in the strategic management process. & 3.82 & 0.907 \\
\hline 3.5.19 & The use of strategic intelligence leads to competitive advantage and innovation. & 3.77 & 0.973 \\
\hline 3.5.11 & Strategic intelligence can assist managers to quantify or qualify strategic choices and articulate strategies. & 3.73 & 1.032 \\
\hline 3.5.10 & Strategic intelligence engages managers in the strategy development process. & 3.64 & 1.293 \\
\hline 3.5.14 & Strategic intelligence can sharpen internal performance monitoring. & 3.45 & 1.101 \\
\hline 3.5.18 & Our strategic intelligence requirements are linked to our strategic objectives and our long term goals. & 3.09 & 1.109 \\
\hline 3.5.1 & Our organisation has a strategic intelligence process in place. & 3.05 & 1.046 \\
\hline 3.5.8 & Managers use strategic intelligence in their strategic planning and decision-making. & 2.86 & 1.207 \\
\hline 3.5.6 & We have a long-term strategic intelligence plan. & 2.82 & 1.296 \\
\hline 3.5.7 & We use strategic intelligence at all levels of decision-making. & 2.73 & 1.120 \\
\hline 3.5.3 & $\begin{array}{l}\text { We fuse our business intelligence, competitive intelligence and knowledge management (to create strategic } \\
\text { intelligence) for use in decision-making. }\end{array}$ & 2.50 & 1.102 \\
\hline 3.5.12 & $\begin{array}{l}\text { Key decision makers are surveyed or interviewed to verify that the intelligence products produced for them } \\
\text { satisfy their needs. }\end{array}$ & 2.41 & 1.098 \\
\hline 3.5.17 & We would consider outsourcing our Strategic Intelligence function. & 2.36 & 1.002 \\
\hline 3.5.2 & Our organisation consolidates all our intelligence into a single intelligence repository. & 2.27 & 1.162 \\
\hline 3.5.15 & Strategic intelligence is a continuous activity in our organisation. & 2.23 & 1.110 \\
\hline 3.5.16 & Our organisation has dedicated human resources to maintain our strategic intelligence function or process. & 2.23 & 1.193 \\
\hline 3.5.13 & Strategic intelligence forms part of our performance appraisal review process. & 1.68 & 0.894 \\
\hline
\end{tabular}

SD, standard deviation. 
$(86 \%)$, websites $(86 \%)$, annual reports $(77 \%)$ and research reports $(72 \%)$. The results further suggest that a large number of organisations do evaluate the reliability and accuracy of their sources of information. Although these data sources can be classified as important and useful, the value of them for competitive intelligence purposes can be debated. The majority of them include information on past activities, which, whilst remaining important, give a predominately historical view of the competitors or environment, which is to be analysed. From a competitive intelligence viewpoint, it is always important to have current, up to date, intelligence on your competitor to allow you to anticipate future activities.

After collecting the data, the most commonly used analytical methods or models used within the organisations to generate competitive intelligence included SWOT (i.e. strengths, weaknesses, opportunities, and threats) analysis and competitor analysis (both with $82 \%$ ), customer segmentation analysis $(72 \%)$, industry analysis $(64 \%)$, and financial analysis and valuation (59\%). The most popular methods used by organisations to distribute and present intelligence results are email $(77 \%)$, presentations $(72 \%)$, and reports $(64 \%)$.

Based on the results we obtained a discouraging view of how tacit knowledge is collected and transformed into explicit knowledge through a knowledge management transformation process within organisations in the long-term insurance industry emerged. Very few organisations had a process in place for the conversion of individually held tacit competence to explicit systems, tools, or templates. The majority of organisations did not have a central intelligence repository to which employees were able to contribute or access knowledge. An equal number of organisations do have and do not have facilities available to their employees to enable the sharing of knowledge, with smaller organisations the least likely to have access to the correct technical infrastructure. A few larger organisations did; however, have a document management system in place as a central store for documents, very little of it was audited or transformed into Intellectual Capital.

The aforementioned results compare well with the results obtained regarding strategic intelligence. We concluded that the majority of respondents do not fuse their business intelligence, competitive intelligence and knowledge management (to create strategic intelligence) for use in decision-making, and do not, on average, consolidate all their intelligence into a single intelligence repository. Intelligence gathered is often not checked for accuracy, nor do the organisations, on average, have dedicated human resources to maintain their strategic intelligence function or process. The lack of consolidation of strategic intelligence is of particular significance in the context of this research, as the discrepancy between the availability and importance of this intelligence for use in the context of strategic management is of vital importance. Without the correct intelligence available, decision making cannot lead to a competitive advantage over competitors.
It is interesting to note the extent of business intelligence processes and the use thereof, and the prevalence of certain competitive intelligence methods and models over others. This can strongly be related to the popularity of business intelligence in the local technological media, the potential advantages thereof, and the prominence of certain models in the curriculums of tertiary institutions.

\section{The use of information systems to create strategic intelligence}

The empirical results suggest that the majority of the respondents did not make use of any specific strategic intelligence information systems, although two respondents did indicate that they made use of internally developed inhouse systems created for specific purposes as the need arose. Strategic intelligence is; however, comprised of a number of subcomponents including business intelligence, competitive intelligence and knowledge management, all of which can make use of systems designed exclusively for them.

As part of the survey, respondents were questioned whether individual systems were used. We found that a large number of different software applications were used by respondents to gather and generate business intelligence. Whilst some respondents indicated that they did not make use of any systems, $73 \%$ of the respondents did indicate that they used various systems ranging from basic business intelligence portals, in-house business intelligence tools (including the use of SQL databases and excel) based upon the data provided by financial, manufacturing, and marketing systems data, management information systems, and a variety of off the shelf business intelligence packages such as Olikview, Cognos, EG Solutions operational management software, Crystal Reports, RADS (Unisys supported) linked to underlying data warehouse, STD Exergy, Hyperion, Business objects, SAP BI, SPSS Clementine is used for Data Mining and specialist visualisation software. Only $32 \%$ of the organisations made use of competitive intelligence Software Applications. This included the use of internally developed systems, the Microsoft suite of products including predominately SharePoint, the electronic storage of documents on servers, and a single respondent indicated their use of a software application named Goldmine. Most organisations do not use specific knowledge management Software applications but a small number made use of in house data stores such as a central file repository on the corporate intranet, Microsoft SharePoint Portal, and in house systems to store and manage knowledge. Further results provided by a single respondent provided detailed information explaining that their operational knowledge, lessons learnt, and technical knowledge are captured in Content Manager, and Microsoft applications. Furthermore, they made use of bodies and structures such as Community of Practice, online learning tools and forums as their Knowledge Management toolkit. Another respondent from a large organisation explained that they did not yet have a centralised approach across their entire organisation; however, individual departments made use of extensive knowledge management practices which were conducted and managed successfully. 
The results indicate a resounding bias in the use of Business Intelligence systems, which are used for the management of the organisations internal business environment. It is, however, concerning that few systems are used for the management of information and more critically, intelligence on the organisations external environment. The lack of Knowledge Management systems further indicate that there is a high possibility of losing valuable Intellectual Capital if not captured and stored in centralised systems. Furthermore, the results indicate a huge deficiency in the use of any systems in smaller organisations. Whilst the costs of larger systems is prohibitive, and in instances prove to be highly complex, a number of systems are available for a low cost or in some instances completely free, and can be maintained at a low cost to the organisations.

Based upon these results, it is imperative that organisations should investigate the advantages that systems could provide in influencing the outcomes of both internal and external forces that impact the competitive nature of the organisations. Accordingly, a well-structured and functioning strategic intelligence system should receive urgent attention in organisations within the long-term insurance industry, in order to provide accurate, timely and structured intelligence for use in decision making.

\section{The extent to which strategic intelligence can address the input needs of the strategic decision-making process}

From the responses it is clear that the respondents believe that strategic intelligence enhances decision-making. Furthermore, the results showed that strategic intelligence is predominately utilised at a strategic level as an input to decision-making, and that strategic intelligence had the greatest impact at a strategic level. We found that strategic intelligence is most commonly used by the organisations as an input to strategic decisions regarding new product development (95\%), when considering competitive advantage (68\%), when determining pricing strategies (64\%), and when considering market entry strategies $(64 \%)$. As a result of the nature of strategic intelligence, the intelligence it provides includes intelligence on the organisations internal, external and knowledge environments which can to a large extent address all the input requirements of the strategic decision making process.

The results made it clear that strategic intelligence could to a large extent address the input needs of the strategic decisionmaking process.

\section{The level of utilisation of strategic intelligence within the South African long-term insurance industry}

The empirical results highlight the fact that strategic intelligence processes are more prevalent in larger organisations. This could simply be the result the lack of human and financial resources available to smaller organisations. The results further suggest that most organisations collect and utilise business intelligence in decision making; however, the results distinctly provide evidence that larger organisations make greater use of business intelligence than smaller organisations. Results further suggest that larger organisations do have a formal competitive intelligence function, whereas smaller organisations, in general did not have a formalised competitive intelligence function. However, results indicate that a high number of organisations do make use of competitive intelligence in decision-making even if no formalised function exists for the management of competitive intelligence. It was found that, with the exception of a few larger organisations, knowledge management is not often utilised and more often constitutes an informal central repository for project and organisational documentation rather than formalised actionable explicit knowledge.

Based upon these results, it seems clear that respondents do believe that strategic intelligence, as a collective, provides better information input to decision makers. Whilst belief is important, reality proved that the majority of respondents did not have a long-term strategic intelligence plan, and that strategic intelligence is not used at all levels of decisionmaking but that a growing proportion of managers felt its importance and thus started to use strategic intelligence in their strategic planning and decision-making.

\section{How strategic intelligence is used and contributes to the strategic management process within the South African long-term insurance industry}

From the empirical results it is apparent that the organisations in the long-term insurance industry do to a large extent, utilise a formalised strategic management process, and therefore recognise strategic management as a necessary activity for business. Furthermore, respondents view information as having strategic value and believe that good strategy hinges on having timely, relevant and high quality information. The results indicate that strategic intelligence is predominately utilised at a strategic level as an input to decision-making, and therefore has the greatest impact at a Strategic level. Respondents further indicated that their strategic intelligence requirements are linked to their strategic objectives and their long term goals.

We found that organisations do attempt to provide their managers with critical and relevant information for strategic decision making; however, smaller organisations that were in greater disagreement do not have the capacity to provide managers with the required information, as larger organisations do. Furthermore, the majority of respondents believe that they do provide their managers with access to information that provides them with a comprehensive and robust perspective on how the organisation is performing, the dynamics at play in the market place, competitor behaviour, stakeholder perceptions, resource availability, and the implications of trends in these areas for the firm. Smaller organisations are; however, at a disadvantage to larger organisations.

The empirical results further showed that organisations do not, on average, have dedicated human resources to maintain their strategic intelligence function or process, and that key 
decision makers are not always surveyed or interviewed to verify that the intelligence products produced for them satisfy their needs. Strategic intelligence was found to not form part of the respondents' performance appraisal review process and is not a continuous activity in the organisations.

\section{How strategic intelligence adds value to organisations within the South African long- term insurance industry}

There are a number of ways in which strategic intelligence can provide value to organisations. The lowest level of value that can be added is in the separate information provided by the components of strategic intelligence, which will now be discussed.

The majority of respondents believed that the availability of business intelligence increased the effectiveness of managerial decision-making, and therefore lead to greater competitive advantage because of their access to valid, reliable and actionable business intelligence, predefined dashboard views of their organisations, and software applications used.

The results indicate the use of competitive intelligence allows the management of organisations to be up to date with emerging technologies in their field of business and the benefits or features of these technologies. Furthermore, it allows organisations to be cognisant of new and pending government legislation and legislative trends that impact their organisation. It was also found that large organisations do in fact analyse their competitors and have up to date profiles of them, whilst smaller organisations mostly did not. Results confirm conclusively that organisations believe that knowledge management assists in creating value out of their organisations intangible assets. Results proved that organisations do view knowledge as a strategic tool, and believe their organisations organisational culture is conducive to the sharing of knowledge and claim to benefit from the processes created to contribute knowledge. A significant amount of organisations require their employees to be personally responsible for the transfer and storage of knowledge in their area of speciality; however, it is clear from the results that there are a number of organisations that have an environment in which employees do not contribute regular information. This is discouraging as employees are often privy to valuable information, whilst those that do encourage contributions could find themselves with a competitive advantage.

The results indicate that the organisations believe that strategic intelligence enhances decision-making and plays a critical role in the strategic management process.

Strategic intelligence therefore provides value by engaging managers in the strategy development process, by assisting management forge better, fact-based decisions, and allows managers to quantify or qualify strategic choices and articulate strategies. This can lead to the sharpening of internal performance monitoring and in conclusion, can lead to competitive advantage and innovation.

\section{Discussion of findings}

The research results have shown that there is a clear discrepancy between the theory advocated by dominant researchers in the field of strategic intelligence and its subcomponents. Whilst many of the organisations surveyed indicated their belief that strategic intelligence and its components did in fact provide advantages to their strategic management and strategic decision-making capabilities, very few had the internal capabilities to fully utilise the suggested methods. A number of respondents further indicated that they were not completely aware of the perceived benefits that strategic intelligence could offer, which could imply that not all organisations are aware of research being conducted by academic institutions. A high number of the organisations; however, did indicate their use of strategic management, business intelligence and to an extent competitive intelligence, indicating the greater awareness around these topics in mainstream media.

We were intrigued by the results for the knowledge management and strategic intelligence questions. Whilst the average mean and standard deviation scores remained within a similar range for the questions on strategic management, business intelligence and competitive intelligence, the scores for knowledge management and strategic intelligence decreased to a lower average range. The results for knowledge management and strategic intelligence substantiate the observation made earlier that the theoretical components of the subject matter are agreed with; however, in reality they are often not formally institutionalised within organisations. The reasons for this could be simply the lack of media attention, or case studies to describe their benefits, or simply a lack of resources to sustain them. We further note that there is a difference in the responses of smaller organisations compared to larger organisations. A number of smaller organisations indicated that they did perceive the value that can be provided by the topics discussed in this research; however, these were not of priority to them because of their resource limitations and obvious smaller market scope. On the other hand, a number of larger organisations show higher scores for the variables indicating the greater ability they have in providing resources, for the perceived competitive advantage gain. As a result of the high competition within the long-term insurance industry, it is clear that organisations need to keep informed of any changes that could lead to them gaining an advantage and increased market share.

Lastly, many of the respondents indicated that they would not be prepared to outsource their strategic intelligence functions, whilst the same number of respondents remained neutral to this possibility. A high level of confidentiality could be a reason for this finding; however, the potential remains for a lower cost solution to be developed that could be used in-house to provide the benefits organisations require. This can be further substantiated by the fact that the majority of respondents believed further research should be conducted to identify better methods of implementing strategic intelligence. 


\section{Conclusion}

\section{Recommendations and future research}

Challenges in the global economy, not to mention the challenges faced in the local South African economy, have amplified the necessity for organisations to remain one step ahead of their competitors. Lack of information and knowledge of decisions taken by all role players within the organisations external, and often internal business environments, has led to the weakening and even failure of organisations. Worldwide, the long-term insurance industry has undergone many changes in its working model with changes focused on increasing the attractiveness of the industry to consumers. With the advent of technological advances that allow all consumers to shop around for the best products and pricing, and the globalisation of markets allowing organisations to compete globally, organisations are required to stay a step ahead of their competitors. To achieve this, a number of strategic decisions will need to be made in order for them to remain stable for the foreseeable future. New products, allowing consumers a greater understanding, flexibility and visibility will be required to attract new clients as well as increase market share and remain competitive.

This research proposed that, through its ability to absorb sources of information, the combined synergy of business intelligence, competitive intelligence, and knowledge management that become strategic intelligence, will allow organisations to incorporate all of their information and intellectual capital into a single database or system which will meet the intelligence requirements of management. The results indicate that whilst the surveyed organisations agreed with this proposition, they did not always conform to its suggested methods.

Our initial proposition was that the identification and utilisation of the most important factors of a strategic intelligence framework would greatly enhance global corporate decision-making and result in competitive advantage and constant innovation within the South African business environment. The research results corroborate this. Much of the research proved that, even if just in theory, organisations do believe that a single model or framework could greatly enhance decision-making resulting in competitive advantage and corporate innovation. The purpose of this research was to identify the current use of strategic intelligence in the long-term insurance industry in the South African environment. We found that, whilst larger organisations are aware of, and do make use of certain models and methods that comprise strategic intelligence or its sub-components; no single organisation within the long-term insurance industry makes use of a holistic and comprehensive strategic intelligence model. However, even without the use of such a model, the organisations surveyed are to a large extent still successful in their endeavours.

The research showed that organisations have not yet fully embraced a model for a cooperative global internal corporate strategic intelligence system or portal that will incorporate all aspects of strategic intelligence into a single, easily manageable resource for management's strategic planning and decision-making process, even though it could enhance their ability to withstand the onslaught of global competitors and expand their business into new markets, protect their local market or identify potential merger or acquisition targets, and increase innovation within the organisations. In providing some understanding of the extent in which strategic intelligence is utilised in the South African longterm insurance industry, identifying the benefits or problems experienced by executive management that have not yet been implemented and used strategic intelligence as an input to the strategic management process, we identified the perceived value strategic intelligence in the decision-making process.

By being able to gather and execute strategic intelligence better than their competition, strategic intelligence can be considered an undeniably powerful source of competitive advantage for organisations of all sizes. By managing and utilising strategic intelligence to anticipate changes successfully, allowing organisations to respond to future trends or opportunities will lead to the longevity of those organisations.

Through the in-depth analyses of the use of strategic intelligence as a strategic management tool in the long-term insurance industry, the following recommendations were identified:

- Organisations should place greater emphasis on the development and application of tangible and intangible assets for use in strategic decision-making.

- Organisations should globalise their outlooks and emphasise the sharing of knowledge across borders to withstand changes as a result of the globalisation of markets.

- Organisations should commence with the creation of an intensive and continuous executive learning aptitude, to enhance current strategic decision-making and to empower future leaders about strategic decisions and intentions with regard to their competitive landscape.

- Organisations should focus on educating all employees of the benefits of business intelligence, competitive intelligence, knowledge management and strategic intelligence.

- Organisations should broaden their approach to strategic intelligence gathering and analysis, and the integration of the intelligence into strategic decision-making.

- Organisations should enhance their internal strategic intelligence capabilities through the creation of formalised departments, processes and/or functions.

- Organisations should utilise the methods and tools provided by strategic intelligence to enable internal and external early warning systems.

- Organisations should place more prominence on intelligence-related information for strategic decision makers; however, a greater dispersion across all levels is required. 
- Executives who took part in this research understand the key role strategic intelligence can play in achieving competitive advantage and future success, and should therefore continue to find ways to improve their approach to strategic intelligence.

The research study has resulted in the awareness of auxiliary areas which could be further refined through supplementary research. The areas identified are:

- The results of the research have shown that strategic intelligence has a conceptual and empirical support to allow it to function as a strategic management tool, with its own management function, or department. Further research should be conducted to ascertain the feasibility of this.

- The literature survey conducted, with the substantiation by the empirical results have confirmed the perceived benefits of strategic intelligence as a tool in the strategic management process. However, few use the consolidated intelligence provided by strategic intelligence as a strategic management tool. Further research could be conducted into the reasons for this.

- Organisations within the long-term insurance industry show their belief in, but lack of commitment to strategic intelligence as a strategic management tool. Research could be conducted to confirm if this perception is valid only within this industry or prevalent across all South African industries, and why strategic intelligence is not used as a tool.

- Respondents indicated that they believed further research should be conducted to identify better methods of implementing strategic intelligence, human resource skills and capabilities required to conduct and analyse strategic intelligence, and strategic intelligence systems. Further research should be conducted to create a comprehensive, yet simple strategic intelligence model that can easily be implemented and customised to the needs of the individual organisations.

- Further research should be conducted into the use of technology to enable effective information use and delivery. Through the creation of a single technological tool that could be used to consolidate the respective components of strategic intelligence into a single repository or databank, which will meet the intelligence requirements of management.

\section{References}

Haag, S., Cummings, M. \& Philips, A., 2007, Management Information Systems for the Information Age, 6th edn., McGraw-Hill/Irwin, Boston, MA.

Hill, C.W.L., 2005, International Business: Competing in the Global Marketplace, 5th edn., McGraw-Hill/Irwin, Boston, MA

Laudon, K.C. \& Laudon, J.P., 2007, Essentials of Business Information Systems, 7th edn., Pearson Prentice Hall, Upper Saddle River, NJ.

Leedy, P.D. \& Ormrod, J.E., 2005, Practical Research - Planning and Design, 8th edn., Prentice Hall, Upper Saddle River, NJ.

Liebowitz, J., 2006, Strategic Intelligence: Business Intelligence, Competitive Intelligence, and Knowledge Management, Auerbach Publications, Taylor \& Francis Group, Boca Raton, FL. doi:10.1201/9781420013900

Liebowitz, J., 2006, What they didn't tell you about Knowledge Management, Scarecrow Press Inc., Lanham, MD.

Life Offices' Association of South Africa, 2008, LOA study reveals South African life insurance gap of more than R10-trillion, viewed 10 June 2009, from http://www. loa.co.za

Life Offices' Association of South Africa, 2008, Consumers spend record R103-billion on life insurance premiums, viewed 10 June 2009, from http://www.loa.co.za

Marchand, D. \& Hykes, A., 2007, 'Leveraging What Your Company Really Knows: A Process View of Strategic Intelligence,' in M. Xu (ed.), Managing Strategic Intelligence - Techniques and Technologies, pp. 1-13, Idea Group Inc., University of Portsmouth, UK.

McGonagle, J.J. \& Vella, C.M., 1999, The Internet Age of Competitive Intelligence, Quorum, Westport, CT.

Montgomery, D.B. \& Weinberg, C.B., 1998, 'Toward Strategic Intelligence Systems', Marketing Management 6(4), 44-52.

Murphy, C., 2005, Competitive intelligence: gathering, analysing, and putting it to work, Gower, Aldershot, Hants, UK.

Pearce, J.A. \& Robinson, R.B., 2005, Strategic Management: Formulation, Implementation and Control, 9th edn., McGraw-Hill, Boston, MA.

Saunders, M., Lewis, P. \& Thornhill, A., 2007, Research Methods for Business Students, 4th edn., Prentice Hall, Essex, UK.

Tham, K.D. \& Kim, H.M., 2002, 'Towards Strategic Intelligence with Ontology-Based Enterprise Modelling and ABC', proceedings of the IBER Conference, Las Vegas, NV, 21-23 August.

The Financial Services Board South Africa, 2007, Annual Report, viewed 10 June 2009, from http://www.fsb.co.za

Xu, M. \& Kaye, R., 2009, 'The Nature of Strategic Intelligence: Current Practice and Solutions', in R. Hunter (ed.), Strategic Information Systems: Concepts, Methodologies, Tools, and Applications (4 Volumes), pp. 1-19, Information Science Reference, Canada. 